\title{
SIERADEN VAN STAND: TWEE KLEDINGORNAMENTEN UIT CHINA
}

In de jaren dertig van de vorige eeuw is de Vereniging via de Eumorfopoulos collectie in het bezit gekomen van twee kledingornamenten, die nu tijdelijk te bezichtigen zijn in de opstelling in het Apeldoorns museum (afb. 1 en 2). ${ }^{1}$ Deze kledingornamenten zijn in China in zwang gekomen tijdens de late Han-dynastie (tweede eeuw, begin derde eeuw n.Chr.), en werden tot in de late zesde eeuw voornamelijk in elitaire kringen bijzonder gewaardeerd. ${ }^{2}$ De ornamenten zijn door hun verfijndheid en het gebruik van kostbare materialen als goud en turkoois zeker sieraden te noemen, maar hebben daarnaast nog een belangrijke symbolische waarde. Deze sieraden, gekenmerkt door hun expressieve afbeeldingen, werden gebruikt als symbool voor status en rang. Zeer waarschijnlijk werden zij op hoeden van leden van de (lokale) hofelite aangebracht om onderscheid te maken in hiërarchie.

\section{Materiaal, techniek en afbeelding}

Hoewel goud immer het symbool was van prestige, status en macht, werd tot aan de Tang-dynastie (618-906) een hogere waarde gehecht aan voorwerpen die waren vervaardigd van brons, jade en lak. Deze materialen genoten een hoge status op basis van een associatie met het onsterfelijke: talrijke bronzen en jaden voorwerpen zijn aangetroffen in graven waar zij dienden als talisman voor de doden op weg naar het hiernamaals. Goud werd veelal gebruikt als decoratief element, voor inleg in bronzen vaten, gordelhaken of lakdozen. ${ }^{3}$ De status van goud beleefde echter een grote opleving tijdens de late Han-dynastie en in de periode daarna, de periode van de Zes Dynastieën (220-589). Als gevolg van een expansiedrift sinds de vroege tweede eeuw voor Christus en een intensief commercieel en cultureel contact met perifere volkeren ten noorden en westen van China, deden nieuwe artistieke ideeën in China intrede. Op het gebied van de sieraadkunst deden zich nieuwe ontwikkelingen voor. Sieraden, zoals gordelhaken, riemgespen en haarspelden werden meer gangbaar en goud steeg in aanzien, voornamelijk als basismateriaal voor de vervaardiging van persoonlijke ornamenten. ${ }^{4}$ Goud was licht en zacht en vormde daardoor een heel geschikt materiaal voor het maken van draagbare en zeer verfijnde sieraden.

Ook de twee ornamenten van de Vereniging bestaan uit goud, zij het gedeeltelijk, aangezien voor de vervaardiging van de ornamenten ook gebruik is gemaakt van brons en semi-edelstenen. De sieraden worden elk gevormd door twee delen die met elkaar verbonden zijn. De basis bestaat uit een dun plaatje brons. Daarbovenop is een dun opengewerkt figuratief paneeltje van goud aangebracht, dat door middel van driehoekvormige tandjes aan het bronzen plaatje is vastgeklemd, waarbij de tandjes om het bronzen plaatje heen zijn gevouwen. 

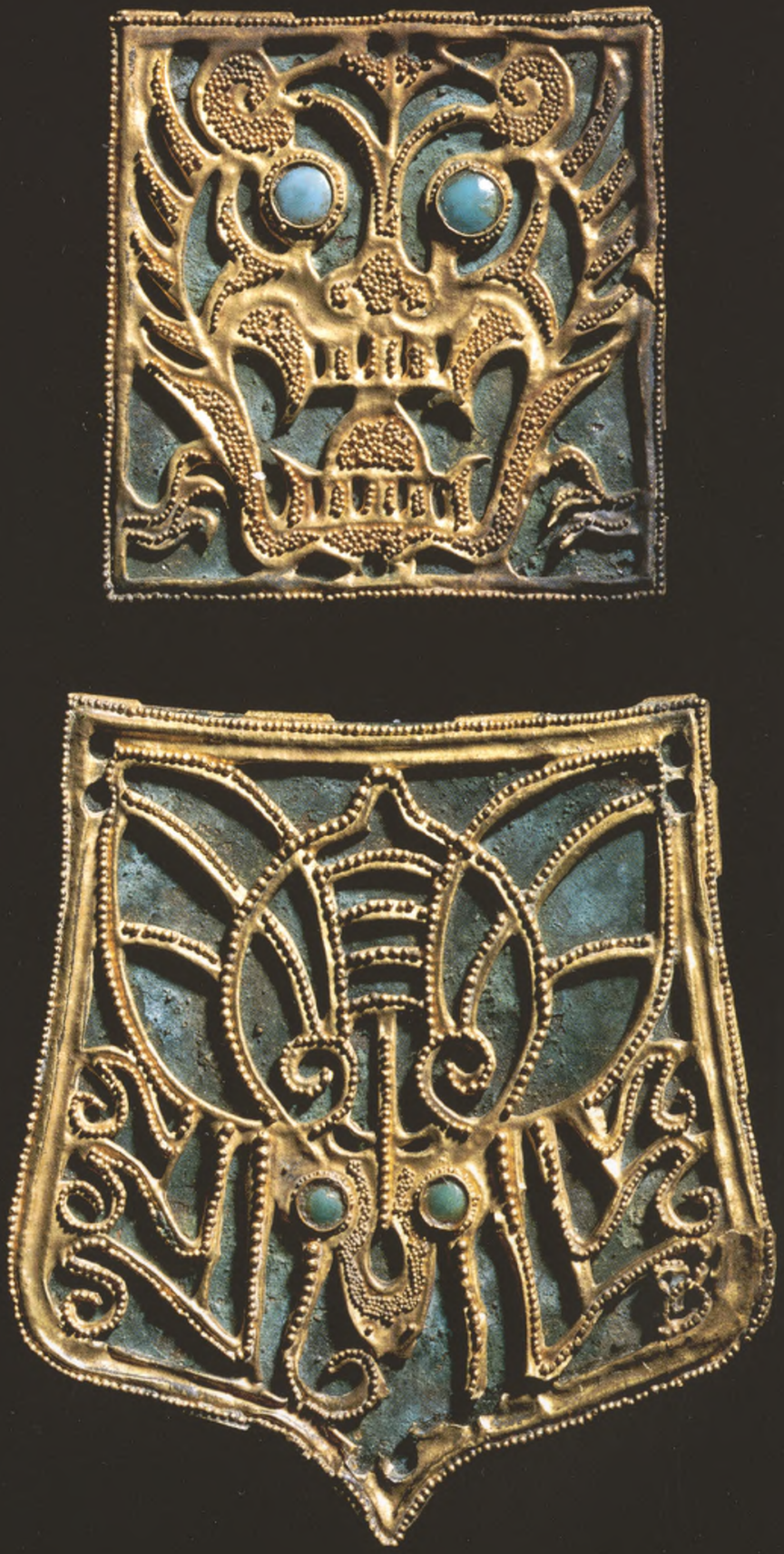
Het geheel krijgt een zeer levendig en verfijnd karakter, omdat er bij de vervaardiging van de ornamenten verschillende smeedkunsten zijn toegepast. De paneeltjes zijn vervaardigd uit een dun plaatje van goud waaruit met zeer

Afbeelding 1 en 2 Kledingornamenten, goud en brons, ingelegd met turkoois. China, late Han-dynastie, begin Zes Dynastieën-periode, derde eeuw.

Rijksmuseum, VVAK, inv.nr. AK-MAK-40 en inv.nr. AK-MAK-4). grote precisie kleine gedeelten zijn weggestoken, zodat uiteindelijk een figuur overbleef. ${ }^{5} \mathrm{Ze}$ zijn omlijst met meerdere dunne randen van goud. De paneeltjes zijn bovendien gedecoreerd met een aaneenschakeling van minuscule gouden kogeltjes, een techniek die granulatie wordt genoemd. Deze techniek werd al vanaf het tweede millennium voor Christus toegepast op Egyptische en Hellenistische sieraden, maar bereikte China pas omstreeks het begin van onze jaartelling via verschillende handelsroutes. Chinese goudsmeden hebben de granulatiekunst zeer waarschijnlijk afgekeken van nomadische stammen uit de noordwestelijke regio, die de techniek al eeuwen eerder op onder meer kronen en oorbellen toepasten. ${ }^{6} \mathrm{Bij}$ de vervaardiging van de ornamenten is gebruik gemaakt van twee verschillende granulatietechnieken. Het vierkante ornament is versierd met strooi-granulatie, waarbij de kogeltjes als het ware zijn uitgestrooid en een vlak vormen. Bij het ornament dat omsloten wordt door een lijst in de vorm van een kroon is tevens gebruik gemaakt van rij-granulatie, een techniek waarbij de gouden kogeltjes aaneengesloten in een rij zijn gerangschikt. ${ }^{7}$

De ornamenten zijn gedecoreerd met twee diermotieven. Eigenlijk is decoratie niet het juiste woord, aangezien de diermotieven zo'n wezenlijk onderdeel uitmaken van de ornamenten dat men kan stellen dat zij zelf het ornament vormen. Het ornament met de kroonvormige lijst bestaat uit een insectachtig dier, zeer waarschijnlijk een cicade. De cicade wordt in China geassocieerd met een lang leven of zelfs onsterfelijkheid, vanwege het feit dat het dier langer leeft dan alle andere insecten. In die zin staat het dier symbool voor voorspoed en geluk. Tijdens de Han-dynastie (206 v.Chr.-220 n.Chr.) fungeerde het motief van een cicade als decoratie op hoeden van dienaren van ambtenaren. Zo'n hoed werd een 'cicadehoed' genoemd, een term die na de Han zou gaan gelden als benaming voor hoge ambtenaren. ${ }^{8}$

De cicade is zeer verfijnd vormgegeven. In een lijnenspel van fragiele gegranuleerde gouden draden zijn vleugels, lichaam, pootjes en voelsprieten exact symmetrisch gevormd. De ogen bestaan uit twee turkooizen en een halfedelsteen die voornamelijk werd aangetroffen in de noordwestelijke regio van China en Tibet. Zij worden omsloten door een opstaand randje van goud. In de omlijsting van het ornament zijn kleine ronde gaatjes te ontdekken die, zoals vergelijkbare sieraden laten zien, ook wel met turkoois waren opgevuld. ${ }^{9}$ Dit is hier echter niet erg waarschijnlijk aangezien geen van de gaatjes een opstaand randje heeft dat de stenen op hun plaats zou moeten houden. Bij vergelijkbare sieraden is daar wel sprake van. Een plausibeler verklaring is dat de gaatjes tot doel hadden het sieraad te bevestigen op een kledingstuk. De gaatjes zijn door zowel het paneeltje als de bronzen ondergrond heen gepriemd, waardoor het mogelijk was om een draad door de gaatjes te steken en op die manier het sieraad op een kledingstuk aan te brengen.

In het vierkante ornament is een wild dier te zien. Uit opgravingen in de westelijke en noordelijke grensstreek van China is gebleken dat wilde dieren een grote bron van inspiratie hebben gevormd voor nomadische stammen. Tijgers, beren, wolven en wilde katten werden veelvuldig als motief aangewend bij de vervaardiging van gespen, gordelhaken of oorbellen, als symbool van moed en kracht. ${ }^{10}$ Vanaf dew vierded eéuw boor Christus trokkerin 


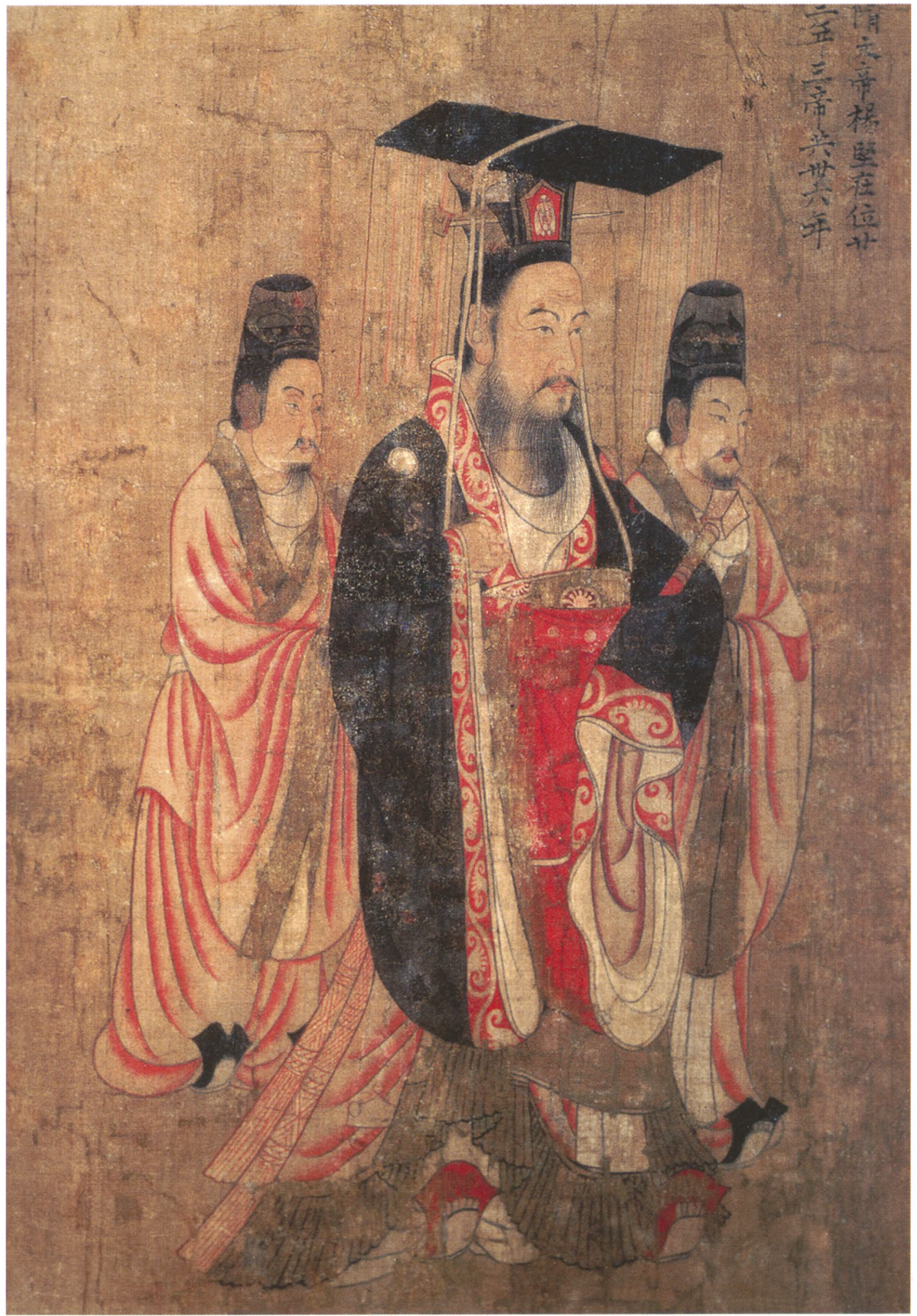


de motieven op deze voorwerpen de aandacht van Chinese handwerkslieden. Chinese sieraden werden vanaf die tijd menigmaal gedecoreerd met dierlijke motieven en werden niet meer alleen vervaardigd in de grensstreek maar ook in centraal China. Een reden voor deze waardering was dat deze dierlijke

\section{Afbeelding 3 \\ Yan Liben (zevende eeuw), Portret van Keizers en Koningen uit Oude Tijden, detail: keizer Wen, inkt en kleur op zijde. Uit: T. Wu, Masterpieces of Chinese Painting from the Museum of Fine Arts Boston: Tang through Yuan Dynasties, Boston, 1996.} motieven in China als symbolen van voorspoed werden beschouwd. Met name sinds de Han-dynastie heerste de gedachte dat hun verschijning een teken was van goedkeuring van de hemel voor het menselijk handelen op aarde."

Het wilde dier in het vierkante ornament is en face uitgebeeld. Aan weerszijden van de kop zijn klauwen te zien. Net als bij de cicade worden zijn ogen gevormd door twee turkooizen. Bij de vervaardiging van dit sieraad is echter minder goud weggestoken dan bij de cicade, waardoor bredere vlakken of lijnen zijn overgebleven. Hierop zijn kleine korreltjes van goud als het ware uitgestrooid. Mede door de bredere vlakken en lijnen krijgt het dier een zeer expressieve uitdrukking. Door zijn open bek en rechtop staande manen lijkt het alsof hij brult.

\section{Het gebruik van de sieraden}

Sinds de vroegste tijden wordt China gekenmerkt door een hiërarchische maatschappij, die is georganiseerd op basis van het verschil in status en rang. Kleding en kledingdecoraties gaven uiting aan een bepaalde maatschappelijke identiteit en status. Voornamelijk vanaf de Zhou-dynastie (1100-222 v.Chr.) werden kledingvoorschriften in steeds sterkere mate gereguleerd.

Deze voorschriften dienden niet alleen om een duidelijk onderscheid aan te geven tussen de adel en het gewone volk, maar meer nog om onderscheid te maken tussen rangen en standen van leden van de adel onderling.

Voorschriften over het gebruik van materialen, kleuren en vormen van kleding, maar ook over het gebruik van hoofddeksels, schoenen en sieraden werden bepaald door de staat. ${ }^{12}$

Om onderscheid te maken in rang en stand werden gewaden van de keizer en ambtenaren vanaf het midden van de eerste eeuw na Christus voorzien van twaalf voorgeschreven kosmische, florale en dierlijke motieven. ${ }^{13}$ Elk van deze motieven stond symbool voor een bepaalde nobele eigenschap of waarde. Zo werd bijvoorbeeld het motief van een draak op het gewaad van de keizer aangebracht, als symbool voor deugdzaamheid. De twee ornamenten gedecoreerd met het wilde dier en de cicade hebben hoogstwaarschijnlijk dezelfde symbolische en onderscheidende functie gehad. Ze werden door leden van de elite gedragen ten teken van voorspoed en als bevestiging van status en macht.

De functie van de ornamenten kwam voornamelijk tot uiting in ceremoniën, bijvoorbeeld wanneer de keizer met zijn gevolg in het openbaar verscheen. Op de schildering Portret van Keizers en Koningen uit Oude Tijden, toegeschreven aan de beroemde hofschilder Yan Liben (d. 673) uit de Tangdynastie (618-906), zijn dertien verschillende keizers en koningen uit verschillende dynastieën in vol ornaat afgebeeld. Niet alleen valt op deze schildering de kledij van de heersers in al zijn pracht en praal te aanschouwen, ook is een glimp te zien van een van de twee sieraden in functie. Op de afbeelding van keizer Wen uit de Sui-dynastie (r. 581-604) valt goed te zien dat een ornament met cicadedecoratie is aangebracht op de kroon van de keizer (afb. 3).$^{14}$ In tegenstelling tot de manier waarop het ornament vaak wordt tentoongesteld, valt uit de schildering afte fêidefr dat heef siéraad met: 


\section{Afbeelding 4}

Kledingornament, goud, ingelegd met parels.

China, Jin-dynastie, vierde eeuw.

Uit: Kaogu 3 (1974), illustraties 7, pl. 3.

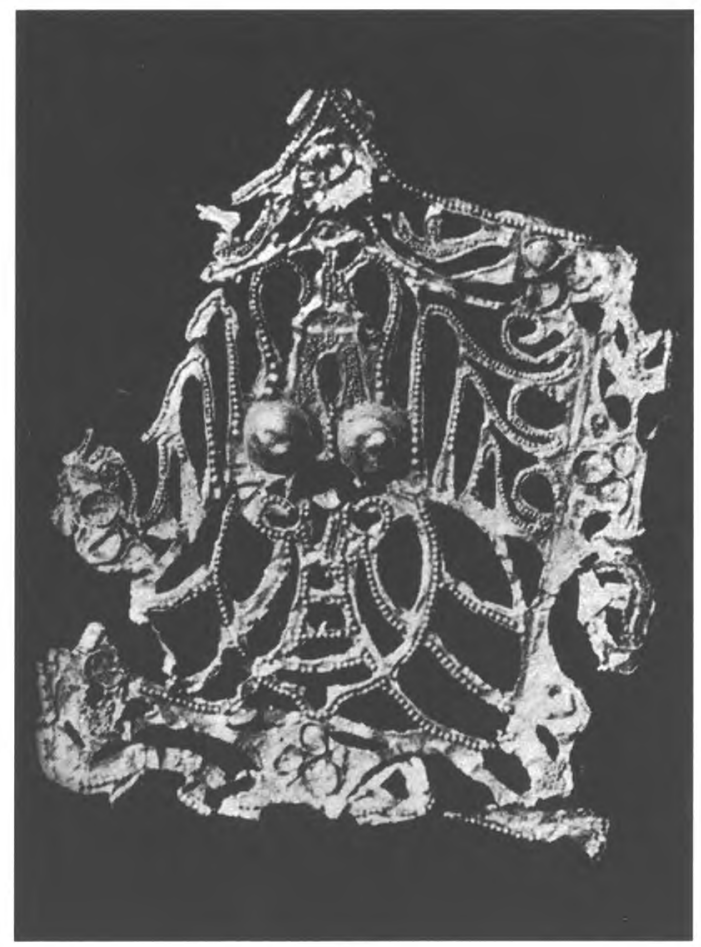

de punt naar boven werd gedragen. Zoals eerder besproken, werden ornamenten als deze vermoedelijk met draad aangebracht op de voorkant van het hoofddeksel. ${ }^{15}$ De keizer droeg het ornament als symbool van een lang en voorspoedig leven dat hem werd gegund als drager van het mandaat van de hemel.

Een andere aanwijzing dat het sieraad op het hoofd gedragen werd, blijkt uit een opgraving van een graf dat dateert uit het midden van de vierde eeuw nabij de stad Dunhuang in het noordwesten van China. Het graf behoorde toe aan vrouwe Ji, lid van een plaatselijke invloedrijke familie van adel. In het graf werd een sieraad aangetroffen dat qua vorm en afbeelding veel gelijkenis vertoont met het sieraad met cicade in het Rijksmuseum. Hoewel de ogen van de cicade niet vervaardigd zijn van turkoois maar van parels (dit toont des te meer de hoge waarde aan die aan dit soort sieraden werd gehecht) en de lijst breder is en met bloemmotieven is gedecoreerd, zijn er veel overeenkomsten te ontdekken. Dezelfde vervaardigingstechnieken zijn gebruikt, het insect is bovendien vrijwel identiek vormgegeven en ook de lijst in de vorm van een kroon met de punt en de lichtgebogen onderkant doet sterk denken aan het sieraad in het Rijksmuseum (afb. 4). ${ }^{16}$ Mogelijk werden dit soort sieraden ook door vrouwen ter onderscheiding gedragen, aangezien vrouwe Ji afkomstig was uit een familie van invloedrijke ambtenaren. Het feit dat het ornament aan het hoofdeinde in de grafkist werd gevonden, wijst er op dat zijn functie juist daar moet worden gezocht. Het is denkbaar dat het wellicht was aangebracht op een hoofddeksel van stof dat aan de overledene werd meegegeven in haar graf, maar dat met de tijd is vergaan. Hoe het ook zij, dat het sieraad werd meegegeven naar het hiernamaals duidt op een bevestiging van de hoge status van de overledene tijdens haar aardse leven. 


\section{Noten}

1. Zie: H.F.E. Visser, 'Twee Chineesche appliques in granulatietechniek', Bulletin van de Vereeniging van Vrienden der Aziatische Kunst, in: Maandblad voor Beeldende Kunsten 12, 1935, pp. 221-224.

2. Vergelijkbare ornamenten zijn oa. te zien in: Kaogu 3, 1974, illustraties 7, pl. 3; Wenwu, 3, 1973, p. 25; B. Gyllensvärd, Chinese Gold and Silver in the Carl Kempe Collection, Stockholm, 1953, pp. 78-79, pl. 18a/b en 20a/b; Yamato Bunkakan, Mayuyama Seventy Years, Tokyo, 1976, vol. 2, p. 45, pl. 77.

3. Het kwam weliswaar voor dat voorwerpen, zoals rituele vaten, in goud werden vervaardigd, toch werden deze vaak naar de vorm van bronzen voorwerpen gemodelleerd. Daarbij diende brons als basismateriaal dat werd verguld. Zie C. Deydier, The Art of the Warring States and Han Periods, London, 1991, pp. 82-87.

4. J. Rawson, The British Museum Book of Chinese Art, London, 1992, pp.184-188.

5. Deze techniek werd veelvuldig toegepast op ornamenten uit de periode van de Zes Dynastieën. Zie: J.M. White en E.C. Bunker, Adornment for Eternity: Status and Rank in Chinese Ornament, tentoonstellingscatalogus Denver Art Museum, 1995, p. 45: chisel-cut shapes and pierced work, p.129 (afbeelding 47) en p. 170 (noot 2).

6. E.C. Bunker, 'Gold in the Ancient Chinese World', Artibus Asiae 53, 1993, pp. 27-50. De Chinese goudsmeden eigenden zich zo'n grote vaardigheid in de techniek toe, dat hun sieraden de aandacht trokken van perifere stammen. De goudsmeden vervaardigden vervolgens sieraden in nomadische stijl die zij verhandelden met de stammen.

7. H.F.E. Visser, op.cit., p. 221.

8. Z. Wu (red.), Ciyuan, Beijing, 1988, p. 1513: 'changuan'.

9. Een vergelijkbaar sieraad met turkooizen die zijn aangebracht in de omlijsting is te zien in B. Gyllensvärd, op.cit., p. 79, pl. 20a.

10. Ook in kleding kwam het motief van het wilde dier terug. In de westelijke provincle Xinjiang is in de plaats Loulan een stuk brokaat aangetroffen met een figuur dat bijna identiek is aan dat van het vierkante sieraad. Zie: Yoshito Harada, Chinese Dress and Personal Ornaments in the Han and Six Dynasties, Tokyo, 1937, p.58. Harada is van mening dat het hier een luipaard betreft.

11. Jenny F. So en Emma C. Bunker, Traders and Raiders on China's Northern Frontier, Seattle en Londen, 1995.

12. Julia M. White en Emma C. Bunker, p.16; Yoshito Harada, pp.1-29.

13. Yoshito Harada, pp.16-17.

14. Wu Tung, Masterpieces of Chinese Painting from the Museum of Fine Arts Boston: Tang through Yuan Dynasties, Boston, 1996.

15. Bo Gyllensvärd komt tot deze conclusie op basis van soortgelijke kledingornamenten uit de Kempe collectie waarbij sprake is van gaatjes langs de randen. Bo Gyllensvärd, p. 19.

16. "Dunhuang Jinmu" (Een Jin-graf uit Dunhuang), Kaogu, vol.3, 1974, pp.191-199, illustraties 7 , pl.3. 